\title{
RANCANG BANGUN SISTEM INFORMASI PENILAIAN SISWA PADA SMA NEGERI 9 KOTA TANGERANG
}

\author{
Dendy Jonas ${ }^{1}$ \\ Endang Sunandar ${ }^{2}$ \\ Satrio Pramudito Sohir ${ }^{3}$ \\ Dosen STMIK Raharja Tangerang ${ }^{1,2}$, Mahasiswa STMIK Raharja Tangerang ${ }^{3}$ \\ Jl. Jenderal Sudirman No.40 Modernland Cikokol, Tangerang ${ }^{1,2,3}$

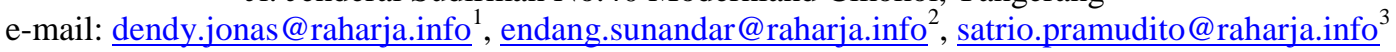

\begin{abstract}
ABSTRAK
Tepat pada tanggal 28 Juni 2003 disepakati oleh Dinas Pendidikan dan Kebudayaan Kota Tangerang untuk didirikan 3 SMA Negeri secara bersamaan yaitu SMAN 8 Tangerang, SMAN 9 Tangerang dan SMAN 10 Tangerang, mulai Tahun Pelajaran 2003/2004. Permasalahan yang dihadapi di SMA Negeri 9 Kota Tangerang adalah pada system penilaian yang berjalan saat ini yaitu dalam satu kelas terdapat 15 mata pelajaran yang diterima oleh siswa dan masing-masing mempunyai nilai yang berbeda. Tak jarang penyimpanan nilai siswa dicatat dan disimpan secara manual. Sehingga membutuhkan waktu yang lama dalam pengerjaannya. Tujuan dari penelitian ini adalah untuk memantau penilaian siswa dengan menggunakan sistem informasi berbasis web pada SMAN 9 Kota Tangerang. Metode yang digunakan dalam penelitian ini yaitu metode pengumpulan data, metode analisa, dan metode perancangan. Metode pengumpulan data dilakukan dengan mengadakan observasi di sekolah, melakukan dokumentasi dengan mempelajari dokumen yang ada, melakukan wawancara kepada pihak terkait. Metode analisa sistem menggunakan Unified Modelling Language (UML) yang digambarkan dengan Use Case Diagram, Activity Diagram dan Sequence Diagram.Metode perancangan menggunakan Unified Modelling Language (UML) dan menggunakan bahasa pemprogramman PHP ( PHP Hypertext Preprocessor). Hasil akhir dari penelitian ini adalah rancang bangun sistem informasi penilaian siswa yang sesuai dengan kebutuhan dan memudahkan user dalam menginput dan membuat laporan nilai siswa.
\end{abstract}

Kata kunci: Informasi, penilaian siswa, laporan nilai siswa

\begin{abstract}
Exactly on June 28, 2003 was agreed by the Education and Culture Department of Tangerang City to be established 3 SMA Negeri simultaneously namely SMAN 8 Tangerang, SMAN 9 Tangerang and SMAN 10 Tangerang, starting Year 2003/2004 Lesson. The purpose of this research is to monitor student assessment by using web-based information system at SMAN 9 Kota Tangerang. Problems in the current system that is in one class there are 15 subjects received by students and each has a different value. Not infrequently the storage value of students recorded and stored manually. So it takes a long time in the process. The method used in this research is data collection methods, analytical methods, and design methods. Methods of data collection conducted by conducting observations in schools, doing documentation by studying existing documents, conducting interviews to related parties. System analysis method using Unified Modeling Language (UML) which is described with Use Case Diagram, Activity Diagram and Sequence Diagram. Design method using Unified Modeling Language (UML) and using PHP programming language (PHP Hypertext Preprocessor). The final result of this research is the design of the student information assessment system that suits the needs and facilitate the user in inputting and reporting the students score.
\end{abstract}


Keyword: Information, student ratings, student grade reports

\section{PENDAHULUAN}

Seiring dengan berkembangnya ilmu pengetahuan, teknologi informasi dan komunikasi pada saat ini, menunjukkan bahwa betapa pentingnya peranan informasi bagi suatu organisasi yang membutuhkan informasi secara tepat, cepat, dan akurat. Teknologi informasi berperan penting pada semua aspek kehidupan terutama bagi mereka yang menekuni dunia kerja. Komputer adalah satu dari sekian banyak alat alternatif teknologi yang dapat diandalkan sebagai alat pengolahan data. Fungsi dari sebuah komputer adalah sebagai alat yang mampu meningkatkan kecepatan pekerjaan sehingga lebih efektif dan efisien dalam hal tenaga maupun waktu dalam pengolahan data.

Kemajuan teknologi komputer dikaitkan dengan kemajuan teknologi pendidikan yang dibuat dan dikembangkan oleh manusia dalam mempermudah setiap pekerjaan dan urusan. Terutama bagi guru yang ingin membuat kurikulum pembelajaran, jadwal pelajaran sekolah, membuat daftar nama siswa, dan membuat daftar nilai siswa yang keseluruhan itu berperan penting demi kelancaran dalam proses pengolahan data kegiatan belajar mengajar (KBM).

Dalam dunia pendidikan sekarang ini secara perlahan kini sistem penilaian siswa pada media komputer sudah menempati peranan penting dalam dunia pendidikan. Ilmu pendidikan yang semakin berkembang dan canggih dalam proses menggunakan program-program, baik dalam media komunikasi, pengolahan data nilai, dan lain sebagainya.

Pada Sekolah SMA Negeri 9 Kota Tangerang terdapat 15 mata pelajaran yang harus dinilai satu persatu secara manual dan membutuhkan waktu yang lama untuk proses pengolahannya sehingga para guru cukup kewalahan dengan cara kerja seperti itu. Dan tidak jarang pula pada saat proses penginputan nilai terjadi kesalahan mulai dari yang kecil hingga kesalahan yang besar. Permasalahan seperti ini tidak dapat dilakukan terus menerus, oleh karena itu perlu adanya sistem penilaian siswa agar masalah yang terjadi dapat teratasi.

Berikut adalah gambar sebuah rapor siswa yang ada pada SMA Negeri 9 Kota Tangerang.

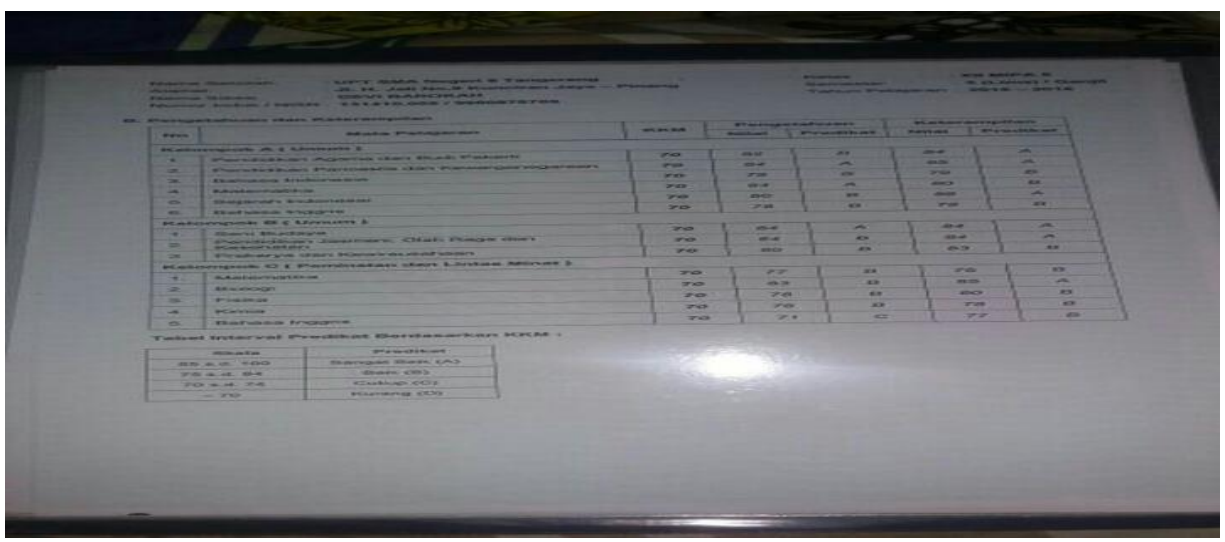

Gambar1. Rapor siswa Capaian dan Kompetensi 


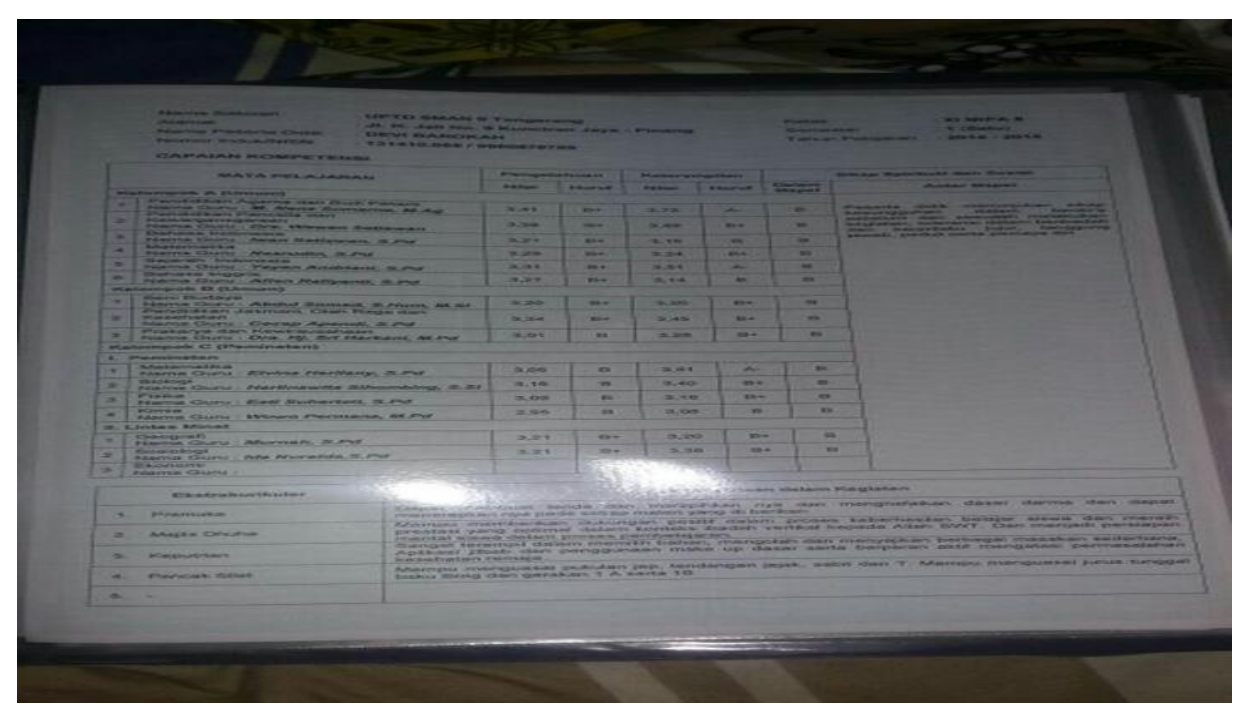

Gambar2. Rapor Siswa Pengetahuan dan Keterampilan

\section{METODE PENELITIAN}

A. Metode Analisa Data

Metode yang digunakan dalam penelitian ini adalah metode deskriptif, yaitu metode penelitian dimana penulis membuat gambaran mengenai kejadian yang bertujuan untuk menggambarkan secara detail, sistematis, dan akurat mengenai hubungan antar kejadian yang sedang diteliti.

B. Metode Pengumpulan Data

1. Metode Observasi (Observation Research)

Metode observasi adalah kegiatan memperoleh data dengan mengamati secara langsung objek yang diteliti oleh penulis. Pengamatan ini dilakukan penulis dengan melihat aktivitas penilaian siswa yang ada di SMA Negeri 9 Kota Tangerang.

2. Metode Wawancara (Interview Research)

Metode Wawancara adalah proses memperoleh keterangan untuk tujuan penelitian dengan cara tanya jawab sambil bertatap muka antara si penanya atau pewawancara dengan si penjawab atau responden dengan menggunakan alat yang dinamakan interview guide (panduan wawancara).

3. Metode Studi Pustaka (Literature Research)

Metode Studi Pustaka adalah proses pengumpulan data dengan melakukan penelitian terhadap berbagai buku, literatur, catatan, serta sebagai bahan laporan untuk masalah yang akan dipecahkan.

\section{PEMBAHASAN}

A. Sistem yang Berjalan

Proses sistem penilaian siswa yang sedang berjalan adalah sebagai berikut:

1. Guru membuat ujian untuk diberikan kepada murid.

2. Murid mengerjakan ujian yang telah diberikan oleh guru.

3. Guru menilai hasil ujian para murid, jika ada murid yang terkena remedial akan mengerjakan ulang ujian dan jika tidak remedial akan lulus. 
4. Guru membuat laporan hasil ujian untuk diberikan kepada wali kelas.

5. Wali kelas membuat laporan yang telah diterima dari guru matapelajaran untuk diberikan kepada wali murid.

6. Wali murid menerima hasil nilai keseluruhan.

B. Sistem yang Berjalan Pada Use Case Diagram

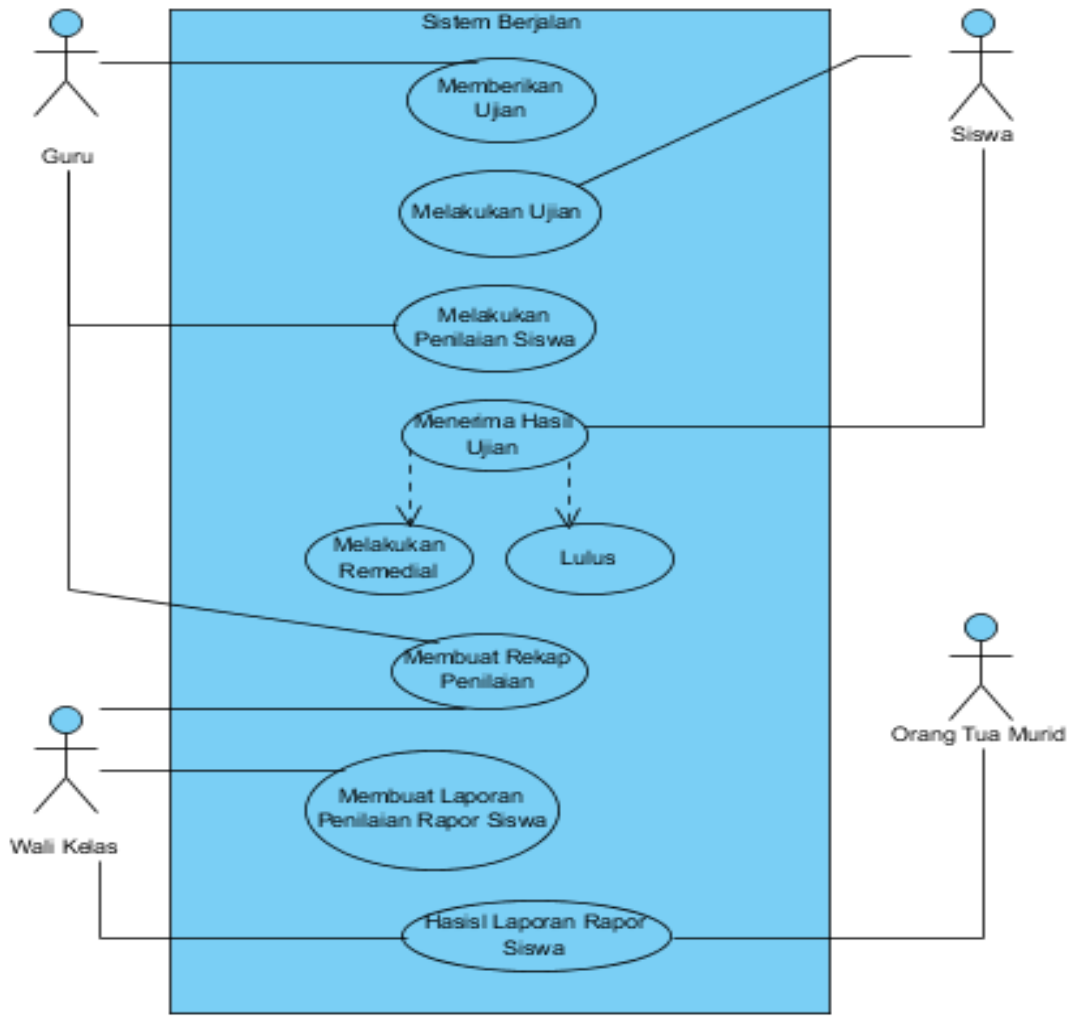

Gambar3. Use Case Diagram

Keterangan:

1. Terdapat sebuah sistem penilaian yang berjalan pada sekolah SMA Negeri 9 Kota Tangerang.

2. Terdapat 4 Actor yang terdiri dari : Guru, Siswa, Wali Kelas, dan Orang Tua Murid.

3. Terdapat 7 Use Case Diagram dan 2 Include Diagram yang dilakukan oleh 4 Actor yaitu: Memberikan Ujian, Melakukan Ujian, Melakukan Penilaian Siswa, Menerima Hasil Ujian, Jika Nilai Kurang Dari 70 akan melakukan Remedial, Jika melewati nilai dari 70 dinyatakan Lulus, Membuat rekap penilaian, Membuat laporan penilaian rapor siswa, Hasil laporan rapor siswa. 
C. Sistem yang Berjalan Pada Activity Diagram

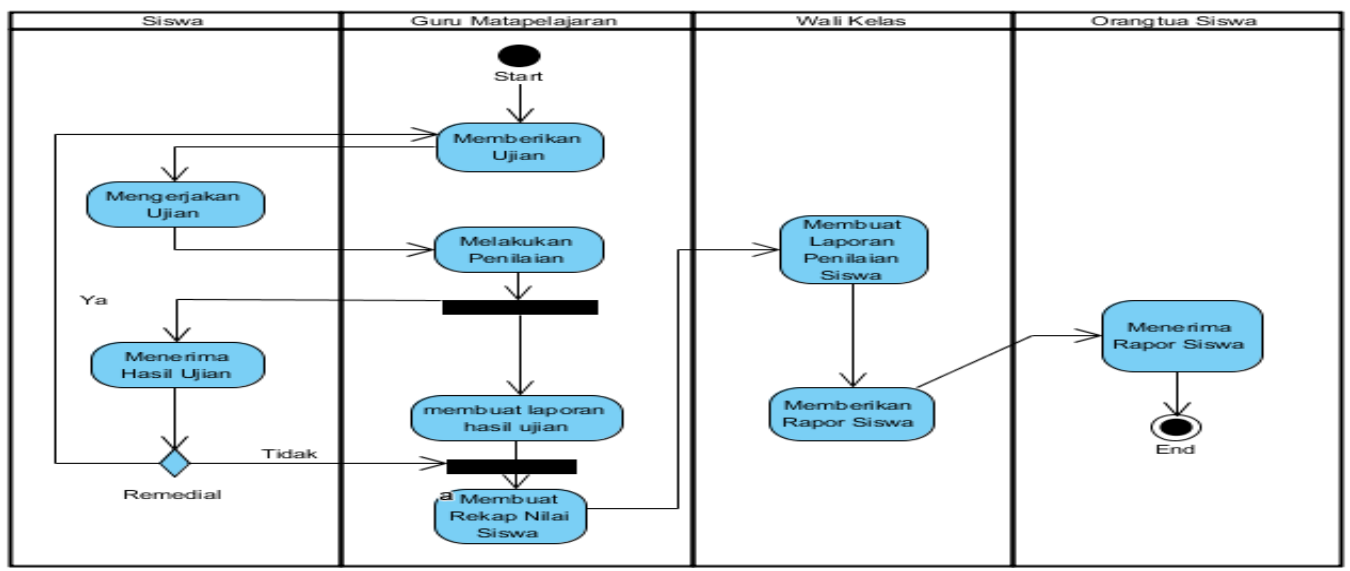

Gambar 4. Activity Diagram

Keterangan:

1. Memiliki 1 buah initial node sebagai start point.

2. Memiliki 9 buah action sebagai proses yang berjalan.

3. Memiliki 1 buah decision sebagai aktivitas yang memiliki kondisi iya atau tidak.

4. Memiliki 1 buah fork sebagai percabangan.

5. Memiliki 1 buah join sebagai penggabungan.

6. Memiliki 1 buah final state sebagai end point.

D. Sistem yang Berjalan Pada Sequence Diagram

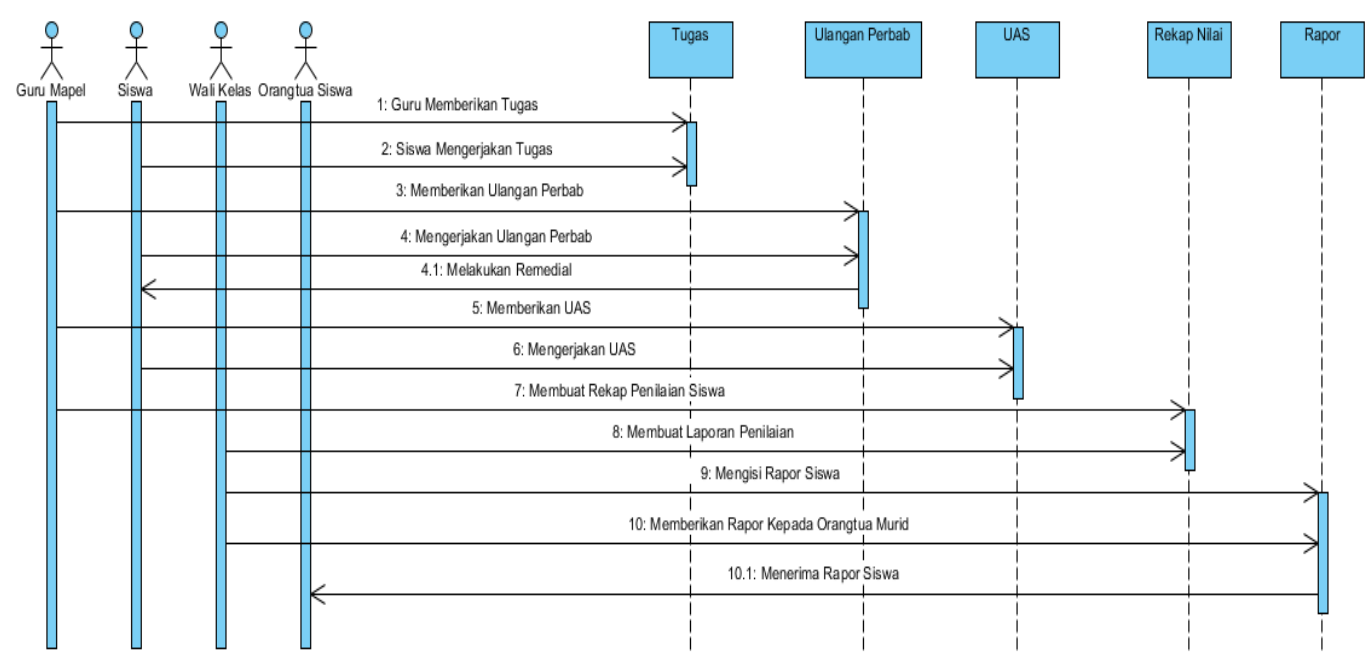

Gambar 5. Sequence Diagram 
Keterangan:

1. 4 actor yang memiliki kegiatan diantaranya: guru mapel, siswa, wali kelas, orangtua siswa.

2. 5 object yang saling berinteraksi yaitu: tugas, ulangan perbab, uas, rekap nilai, rapor.

3. 12 message spesifikasi dari komunikasi antar objek yang memuat informasi tentang aktifitas yang terjadi, kegiatan yang biasa dilakukan oleh actor - actor tersebut.

E. Permasalahan yang dihadapi

Setelah melakukan analisa proses penilaian yang ada pada SMAN 9 Kota Tangerang, permasalahan yang sedang dihadapi oleh SMAN 9 Kota Tangerang terbilang cukup merugikan dikarenakan di era globalisasi sekarang proses penilaian siswa masih menggunakan manual yaitu harus di input satu persatu oleh para guru sehingga memakan waktu yang tidak sedikit dan resiko terbesar pada proses tersebut adalah hilangnya data yang telah diselesaikan.

F. Solusi yang diberikan

Dalam proses perencanaan sistem penilaian, peneliti memberikan masukan untuk membuat sistem informasi penilaian siswa. Dengan sistem informasi penilaian siswa maka diharapkan sumber daya yang ada seperti komputer, internet dapat digunakan secara optimal. Agar sistem penilaian kedepannya bisa berjalan dengan lebih cepat, tepat, dan akurat dan bisa meringankan tugas para guru untuk melakukan proses penginputan nilai para siswa.

\section{IMPLEMENTASI}

A. Rancangan Aplikasi

Dalam rancangan sistem informasi penilaian siswa, penulis akan membuat rancangan aplikasi yang sesuai dengan kebutuhan para guru, berikut adalah rancangan yang dibuat oleh penulis.

a. Rancangan Login Admin

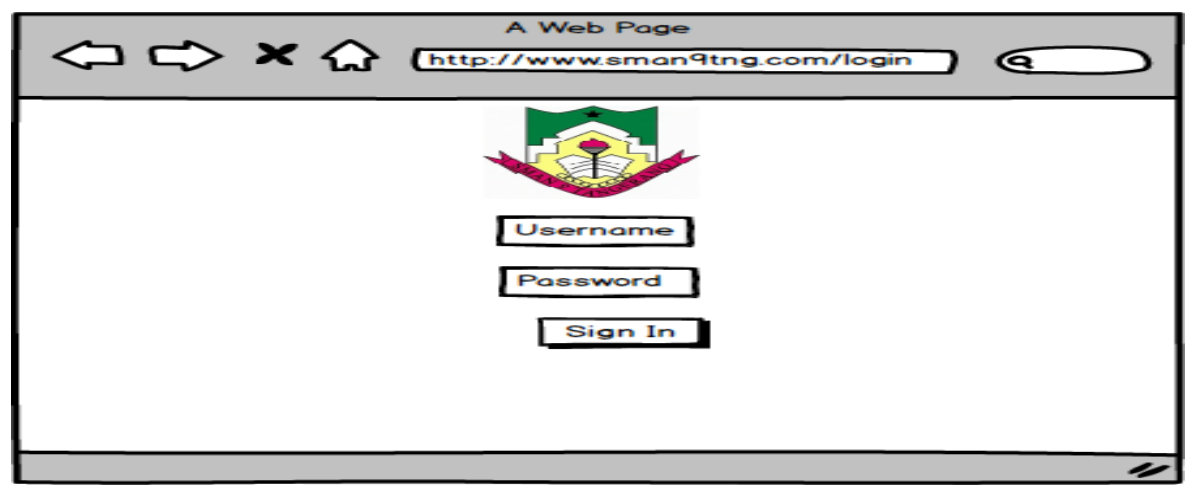

Gambar 6. Tampilan Login

Gambar diatas merupakan tampilan login yang digunakan oleh user jika ingin memasuki sistem penilaian dengan mengisi kolom username dan password. 
b. Rancangan Home

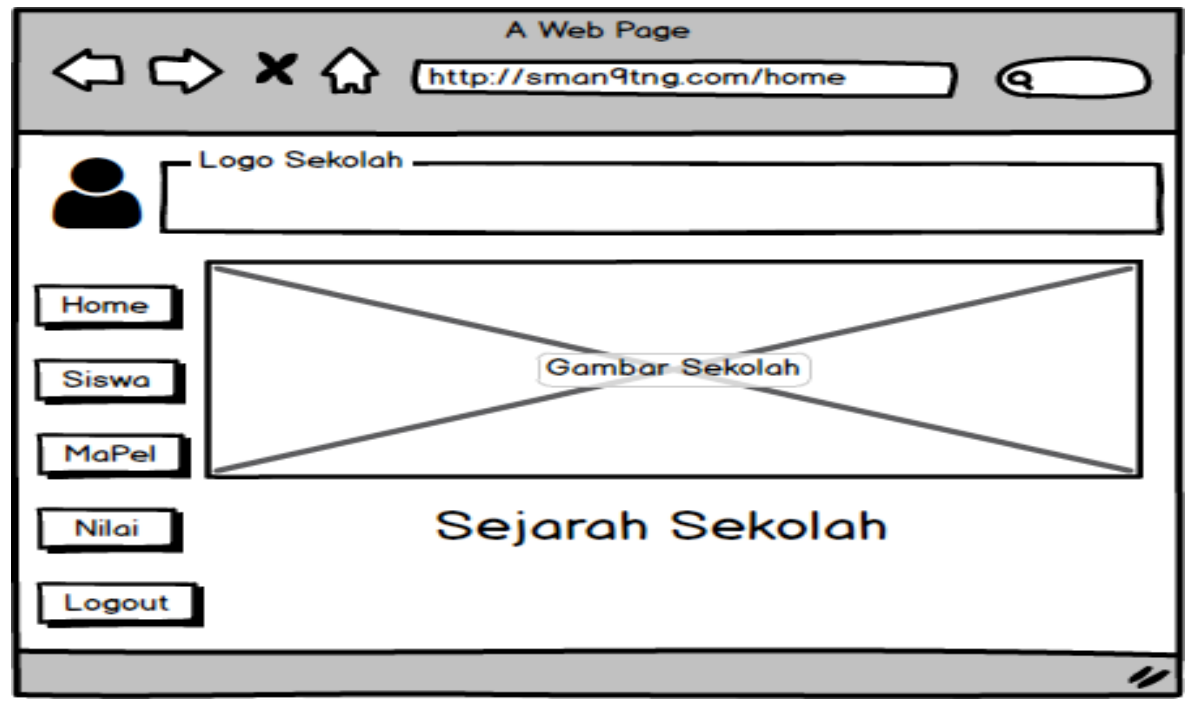

Gambar 7. Tampilan Home

Gambar diatas merupakan tampilan home yang digunakan oleh user ketika memasuki sistem penilaian dan meng klik menu home dan terdapat gambaran dan sejarah sekolah.

c. Rancangan Siswa

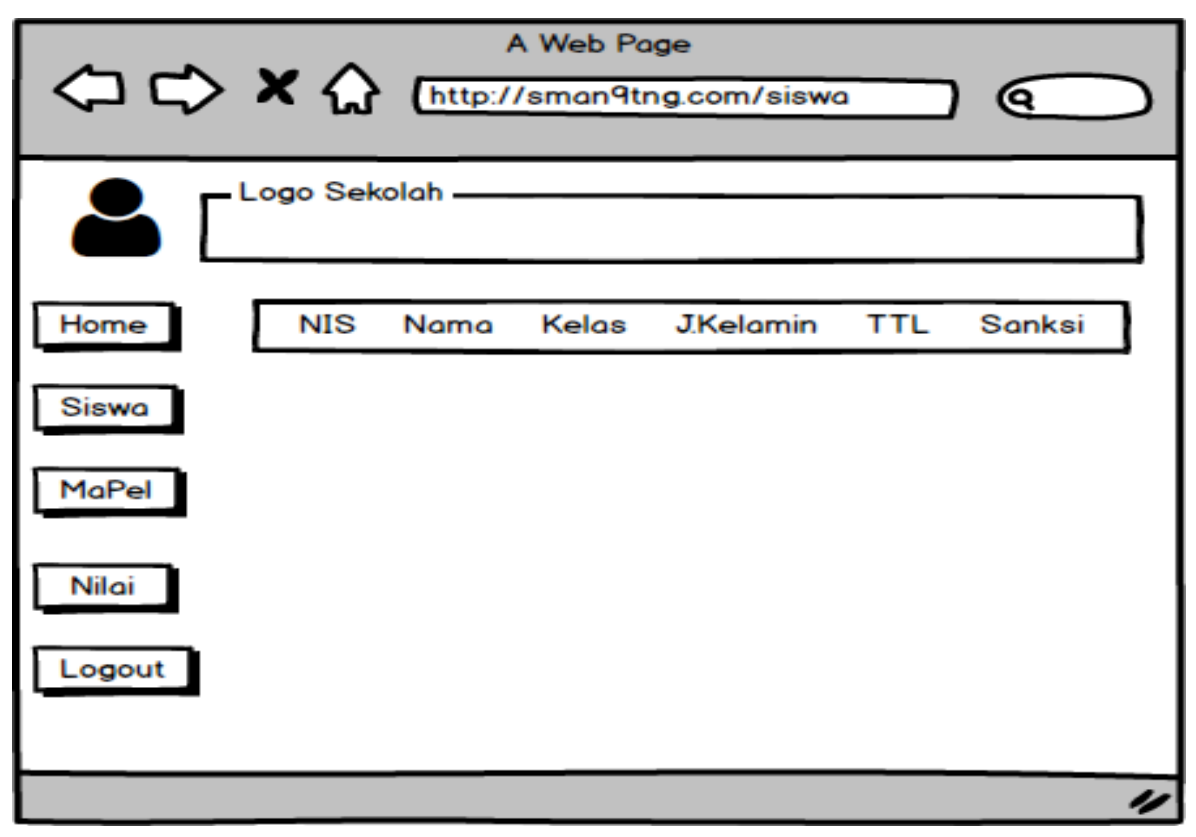

Gambar 8. Tampilan Siswa

Gambar diatas merupakan tampilan siswa yang digunakan oleh user untuk meng input data diri siswa dan terdapat menu NIS, Nama, Kelas, J.Kelamin, TTL, dan Sanksi untuk memudahkan guru dalam proses input data siswa. 
d. Rancangan MaPel

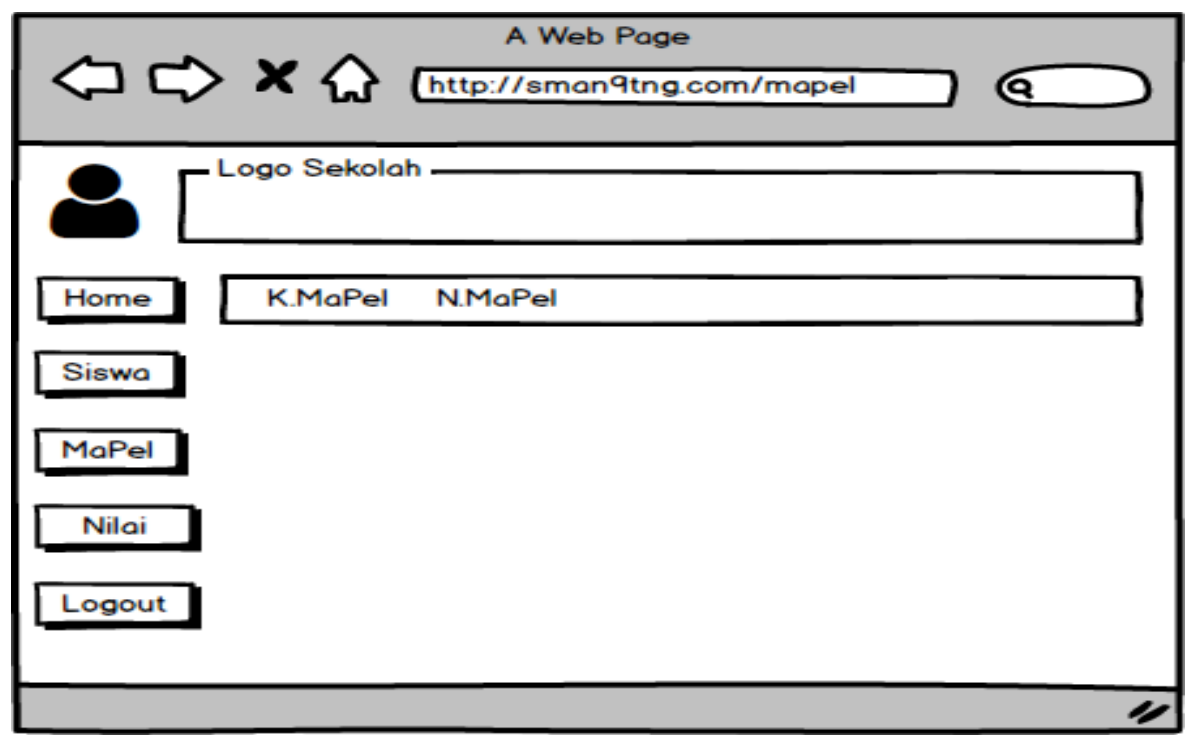

Gambar 9. Tampilan MaPel

Gambar diatas merupakan tampilan MaPel yang digunakan oleh user untuk meng input mata pelajaran yang ada disekolah dan terdapat menu Kode.MaPel, Nama.MaPel, untuk memudahkan guru dalam proses input mata pelajaran.

e. Rancangan Nilai

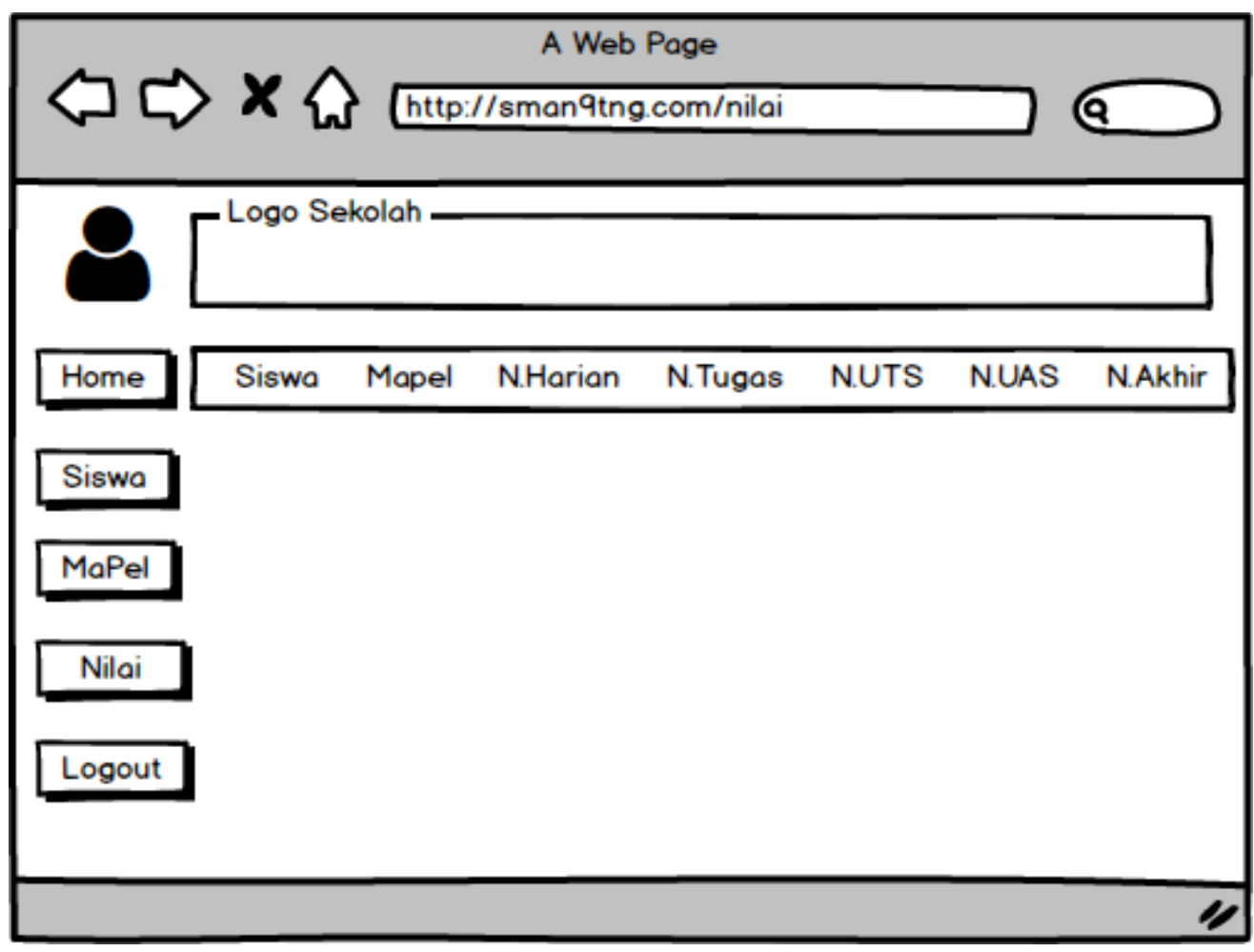

Gambar 10. Tampilan Nilai 
Gambar diatas merupakan tampilan nilai yang digunakan oleh user untuk meng input nilai dari setiap siswa yang ada disekolah dan terdapat menu siswa, mata pelajaran, nilai harian, nilai tugas, nilai uts, nilai uas, dan nilai akhir.

f. Rancangan Logout

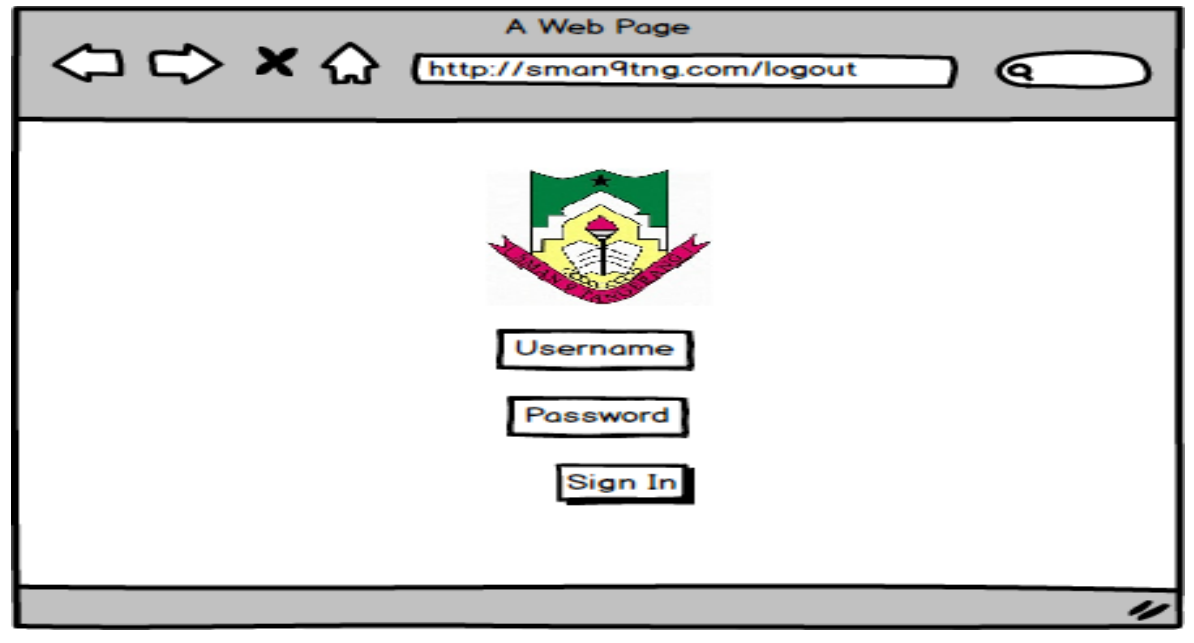

Gambar 11. Tampilan Logout

Gambar diatas merupakan tampilan logout untuk keluar dari sistem penilaian setelah selesai melakukan input data.

\section{KESIMPULAN}

Berdasarkan hasil penelitian dari sistem informasi penilaian siswa pada SMA Negeri 9 Kota Tangerang, maka penulis dapat menarik kesimpulan sebagai berikut:

1. Berdasarkan hasil analisa yang dilakukan peneliti dapat disimpulkan yaitu proses sistem penilaian yang ada pada SMA Negeri 9 Kota Tangerang masih manual atau belum terkomputerisasi dengan baik. Hasil penilaian yang didapat harus melalui beberapa proses terlebih dahulu sehingga menghasilkan nilai rapor para siswa. Proses pertama yaitu terdapat 15 mata pelajaran dari para siswa yang harus diambil, kemudian proses yang kedua para siswa mengikuti pengambilan nilai seperti tugas harian, ulangan per bab, ulangan per semester, ujian praktek, ulangan akhir dan dari pengambilan nilai tersebut para guru akan menilai satu persatu dari para siswa yang nantinya akan diolah dan diberikan kepada wali kelas para siswa. Dan proses yang terakhir atau yang ketiga para wali kelas akan melakukan proses peng inputan nilai yang sudah diberikan para guru mata pelajaran ke dalam buku rapor siswa sebagai nilai akhir para siswa.

2. Keakuratan dan efisiensi sistem penilaian siswa pada SMA Negeri 9 Kota Tangerang cukup beresiko karena masih menggunakan sistem manual dan belum terkomputerisasi dengan benar sehingga akan berdampak buruk bagi kedua belah pihak seperti keterlambatan hasil nilai para siswa dan hilangnya data yang telah dibuat. Dengan proses yang masih menggunakan excel para guru dan para wali kelas harus bekerja ekstra dalam proses penginputan nilai sehingga kurang efisien dalam hal ketepatan dan kurangnya keakuratan dalam hal pendataan nilai siswa.

3. Proses penerapan sistem terkomputerisasi terlebih dahulu harus didukung dengan perangkat keras (hardware) dan perangkat lunak (software) yang memadai agar tidak terjadi masalah dalam proses penyimpanan data para siswa maupun pada saat proses penginputan. Dampak positif untuk setiap guru maupun wali kelas dalam menggunakan sistem yang memadai ialah tepat waktu dalam menghasilkan nilai bagi para siswa dan 
terjaminnya penyimpanan data yang dilakukan oleh para guru dan wali kelas sehingga para siswa dapat dengan cepat mengetahui hasil nilai yang telah dilaksanakan.

\section{DAFTAR PUSTAKA}

[1] Arifin, Zainal. 2012. Konsep dan Model Pengembangan Kurikulum. Bandung : PT. Remaja Rosdakarya.

[2] Nursaid dkk. 2015. "Pembangunan Sistem Informasi Penilaian Hasil Belajar Siswa Pada SMA Negeri 2 Rembang berbasis Web". Jurnal IJNS Vol 4 no 2 Tahun 2015.

[3] Rivai, Ainur, Dani dkk. 2014. "Pembangunan Sistem Informasi Pengolahan Data Nilai Siswa Berbasis Web Pada SMK Miftahul Huda Ngadirojo”. Jurnal IJNS Vol 3 No 2 Tahun 2014.

[4] Sri Rahayu, El Rayeb. 2011. Sistem Penilaian Matakuliah Berbasis Web pada Perguruan Tinggi. Vol. 1 No. 2, November 2011. Diambil dari: http://www.jurnaldigit.org/index.php/DIGIT/article/view/9 (18 Desember 2017).

[5] Wardani, Susy Kusuma. 2013. Sistem Informasi Pengolahan Data Nilai Siswa Berbasis Web Pada Sekolah Menengah Atas (SMA) Muhammadiyah Pacitan. Indonesian Jurnal on Networking and Security (IJNS) Volume 2 No. 2. ISSN:2302-5700.

[6]. Yulianto, Eko, Ahmad Yani. 2017. "Sistem Informasi Akademik Penilaian Berbasis Web Pada SMA Mandiri Balaraja -Kab.Tangerang”. Jurnal KNiST Maret 2017, pp. 607 611. 